Laser Chem. 1988, Vol. 8, pp. 349-375

(C) 1988 Harwood Academic Publishers GmbH

Photocopying permitted by license only

Reprints available directly from the Publisher

Printed in the United Kingdom

\title{
Comparisons of Infrared Multiple Photon Reaction Yields of Some $\mathrm{C}_{3}-\mathrm{C}_{6}$ Hydrocarbons
}

\author{
MURTHY L. YERRAM and ROBERT W. CARR JR. \\ Department of Chemical Engineering and Materials Science, University of \\ Minnesota, Minneapolis, MN 55455
}

(Received March 18, 1988; in final form April 19, 1988)

\begin{abstract}
Low pressure $(53 \mu)$ infrared multiple photon decomposition of several hydrocarbons requiring large fluences to produce measurable decomposition was investigated. Cyclopropane, propylene, methylcyclopropane, cis- and trans-2-butene, vinylcyclopropane, cyclopentene and 1-methylcyclopentene exhibit wide variations in reaction product yield and the spectral dependence of yield at constant pressure and fluence. The role vibrational state density, torsional vibrations and low intensity absorption cross section play in determining yields was examined. The results show the complex interplay of factors affecting multiple photon decomposition. Although the maximum observed yields tend to increase with increasing vibrational state density and absorption cross section, they were poorly correlated with either state density or cross section. The dependence of yield upon excitation wavenumber revealed several unexpected features which indicate that low energy vibrational level structure must be the dominant factor in determining yields. Also, the data suggest that torsional vibrations can ease the excitation bottleneck.
\end{abstract}

KEY WORDS: IR multiphoton, decompositions, hydrocarbons.

\section{INTRODUCTION}

Though the field of infrared multiple photon excitation (MPE) and dissociation (MPD) has received attention in the past decade, the 
complex photophysics of absorption of the first few quanta in the discrete vibrational level region, and coupling into the quasicontinuum (QC) by intramolecular vibrational energy redistribution (IVR) of the initial pumped mode excitation precludes any a priori determination of the facility of MPE and MPD in molecules possessing a discrete level excitation bottleneck. Molecules in which such a bottleneck is found are often referred to as "small" molecules. Current understanding of MPE suggests that the excitation bottleneck in a small molecule reflects its sparse density of vibrational states, which necessitates several discrete level transitions before the onset of the QC. Discussions of the dynamics of discrete level excitation can be found in Refs. $1-5$.

Vast differences in the MPD yields and in the ease of excitation are apparent in molecules reported in the literature. Generally, more facile excitation is observed with increasing size of the molecule, smaller molecules showing intensity dependent excitation changing over to fluence, or time integrated intensity dependent excitation in large, heavy molecules. ${ }^{6}$ McAlpine et al. ${ }^{7}$ reported that on pumping the $-\mathrm{OH}$ stretch mode in a series of molecules with a HF laser the same degree of excitation required lower fluences as the group attached to the $-\mathrm{OH}$ is made larger or heavier. This effect is ascribed to the onset of the QC at lower excitation energy in larger molecules by virtue of their higher density of states.

Apart from size, molecular structure can have significant influence in the excitation process. For instance, the presence of low frequency modes, such as the internal rotation of a methyl group, that make large contributions to the state densities can bring down the onset of the $\mathrm{QC}$, thus decreasing the number of discrete level transitions. Also, these low frequency modes have significant thermal populations in their excited levels that can provide additional pathways for excitation. Furthermore, the vibrational energy level pattern may in some cases provide adventitious wavelength dependent excitation paths.

Since low level excitation is rate limiting in small molecule MPE, it is in small molecules that the effects of molecular structure (vibrational energy levels) on lower level excitation mechanisms will be manifested in such experimental observables as average excitation energy and MPD yield. Parameters that affect the degree of bottleneck should be revealed through systematic investigation of small molecules. Although a number of individual molecules have been investigated in 
detail so far, they are for the most part not readily amenable to comparisons as a variety of experimental conditions are usually involved. Systematic investigations where molecular size and molecular structure have been varied in a regular way are of limited availability at present.

In a previous investigation, ${ }^{8}$ we found that 1 -methylcyclopentene irradiations resulted in larger dissociation yields than cyclopentene irradiations under similar experimental conditions. Similar modes with comparable absorption strengths were excited, both molecules having similar Arrhenius parameters. The observed yield enhancement was attributed to the larger density of vibrational states in 1-methylcyclopentene due to the presence of a methyl group. This observation prompted us to initiate an investigation of MPD and MPE of some low molecular weight hydrocarbons.

We have undertaken a comparative study in several molecules having not dissimilar vibrational frequency patterns as part of an investigation of the influence of vibrational state density, lower vibrational manifold level spacings and linear absorption band intensity on the MPD and MPE of small molecules. In this paper we present and compare low pressure (approximately collisionless during the laser pulse) multiple photon reaction yields at a number of $\mathrm{CO}_{2}$ laser lines in cyclopropane, propylene, methylcyclopropane, cyclopentene and 1-methylcyclopentene at constant experimental conditions (pressure and fluence) along with previous data on vinylcyclopropane ${ }^{9}$ and cisand trans-2-butene. ${ }^{10}$ MPE results will be the subject of a later report. All of these species, with the exception of vinylcyclopropane and trans-2-butene, require focused laser radiation to produce measurable yields. Our objective here was to ascertain whether the reaction yields, as a readily accessible experimental indicator of excitation to high vibrational energy levels, correlate with vibrational state densities and absorption cross-sections in bottlenecked molecules. The isomeric pairs, cyclopropane and propylene, and cyclopentene and vinylcyclopropane are compared in an attempt to assess the influence of an internal rotor. The results clearly show the complexity of infrared multiple photon photochemistry due to the interplay of factors affecting the rate of vibrational excitation. While the expected role of state density and absorption cross section are apparent for some of the data, there are many exceptions that clearly indicate the need for caution in making generalizations. 


\section{EXPERIMENTAL}

The chemical species studied here are from the following sources: Phillips Petroleum Co. propylene (99.99\%), Matheson cyclopropane (99\%), ICN Pharmaceuticals Inc. methylcyclopropane (98\%), Chemical Samples Co. cyclopentene (99.9\%) and Aldrich Chemical Co. 1-methylcyclopentene (96\%). All reactants were used directly without any further purification. The liquid samples were degassed by a few freeze-pump-thaw cycles prior to use.

The radiation source is a grating tuned, multimode, Lumonics 101-2 TEA CO 2 laser. A lasing gas flow of $24.7,2.4$ and $0.7 \mathrm{ft}^{3} / \mathrm{hr}$ (at $10 \mathrm{psig}$ and $21^{\circ} \mathrm{C}$ ) of $\mathrm{He}, \mathrm{CO}_{2}$ and $\mathrm{N}_{2}$ gases respectively was employed. The temporal pulse shape viewed on an oscilloscope with a Rofin model 7400 photon drag detector consists of an intense initial spike of $\sim 125 \mu \mathrm{s}$ FWHM followed by a weak decaying tail lasting typically $2 \mu \mathrm{s}$. When the photon drag detector (with a manufacturer stated response time $\leqq 1 \eta \mathrm{s}$ ) output was digitized with a Gould Biomation Model 6500 Waveform Digitizer using a $2 \eta \mathrm{s}$ sampling interval, the longitudinal mode structure of the pulse could be observed (see Figure 1). Due to the randomly varying phases of these longitudinal modes (non mode-locked) the temporal shape changes pulse to pulse. A single longitudinal mode is observed to have a halfwidth of $\sim 5 \eta \mathrm{s}$. This sets the time duration to be considered for coherent processes. Due to the overlapping of these modes, their number in a pulse could not be counted reliably. By recording a number of pulses we counted a maximum of 12 longitudinal modes in some of the better resolved traces at typical laser settings. This gives a way of estimating the laser linewidth. The mode separation inside the laser cavity is given by $c / 2 l$ which for our laser is $\approx 68 \mathrm{MHz}$, thus giving a lower bound on the linewidth $\left(\Delta v_{1}\right)$ as $12 \times 68 \mathrm{MHz} \approx 0.027 \mathrm{~cm}^{-1}$.

The laser beam is passed through a $1.99 \mathrm{~cm}^{2}$ circular aperture before being focussed with a $40 \mathrm{~cm}$ focal length $\mathrm{Ge}$ lens through the center of a $2.5 \mathrm{~cm}$ diam. by $30 \mathrm{~cm}$ cylindrical Pyrex reaction cell fitted with $\mathrm{NaCl}$ windows. The laser pulse energy was monitored with a Scientech 36-001 disc calorimeter and model 362 power/energy meter which was connected to a home built pulse counter/integrator. ${ }^{11}$ The pulse fluences $\left(\mathrm{J} / \mathrm{cm}^{2}\right)$ reported here are based on the aperture cross sectional area after taking into account the losses due to the lens and the front window of the reaction cell. Hence the local fluence anywhere inside 

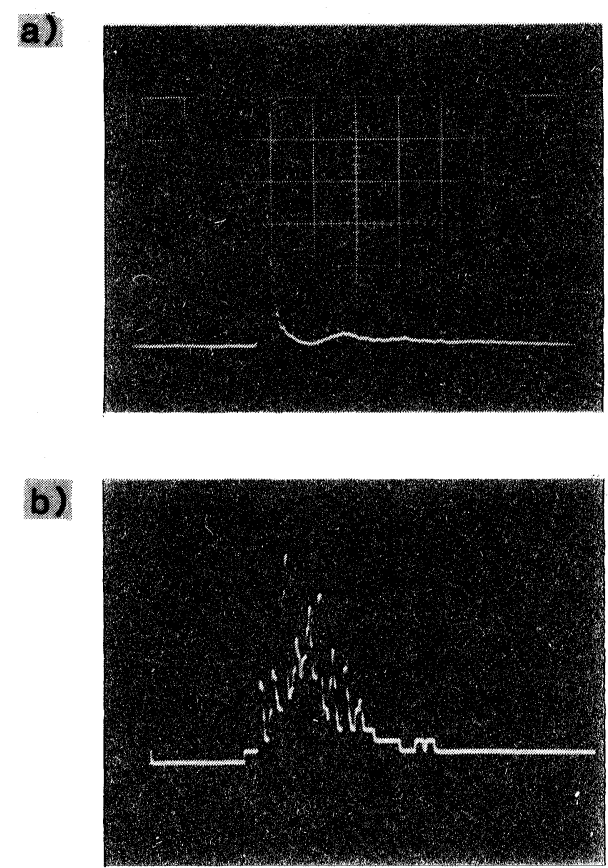

Figure 1 Temporal pulser shape with a photon drag detector (resp. time $\sim 1 \eta \mathrm{s}$ ), (a) time scale $500 \eta \mathrm{s} / \mathrm{div}$. (b) digitized at $2 \eta \mathrm{s}$ sampling interval; time scale of photograph $50 \eta \mathrm{s} / \mathrm{div}$.

the cell can be obtained by multiplying the reported fluence by the ratio of aperture cross-sectional area and the local beam crosssectional area. The approximate focused beam geometry was reported $^{8}$ as a circular hyperboloid. The beam diameter at the entrance window was $0.6 \mathrm{~cm}$ and at the focal region approximately $0.1 \mathrm{~cm}$.

The reaction yields reported here are for $10^{3}$ pulse irradiations in neat reactant gas pressures of $53 \pm 2$ mtorr. After irradiation, the products were analyzed using a flame ionization detector on a HewlettPackard 5730A gas chromatograph and 3390A reporting integrator. The following GC columns and conditions were employed: $20 \mathrm{wt} \%$ dimethylsulfolane on 60/80 Chromosorb $\mathrm{P}$ in a 6-ft, 1/8-in. o.d. column for cyclopentene product analysis at room temperature, the same column at $35^{\circ} \mathrm{C}$ for 1 -methylcyclopentene, a 6-ft, 1/8-in. o.d. Porapak 
$\mathrm{Q}$ column at $60^{\circ} \mathrm{C}$ for cyclopropane, a $36-\mathrm{ft}, 1 / 8$-in. o.d. silver nitrateglycerol on Chromosorb $\mathrm{P}$ column at $35^{\circ} \mathrm{C}$ for methylcyclopropane, and a 9-ft, $1 / 8$-in. o.d. Porapak $\mathrm{Q}$ column at $85^{\circ} \mathrm{C}$ for propylene product analysis. The FTIR spectra were measured at $2 \mathrm{~cm}^{-1}$ resolution in 10.65 torr of neat gas and $10 \mathrm{~cm}$ path length. The laser lines were verified with an Optical Engineering Spectrum Analyzer.

In reporting the yields, FID response was assumed proportional to the number of carbon atoms in a molecule. The carbon number and product identification was checked by retention time data, and by direct injection of authentic samples of expected products based on prior reports on some of these molecules. ${ }^{8-14}$ In some instances GC-MS analysis was performed to ascertain the product identity.

\section{RESULTS}

\section{Reaction products}

Reports on some aspects of MPD of cyclopentene ${ }^{8}$ cyclopropane ${ }^{12-14}$ and propylene ${ }^{14,15}$ have appeared before. The major products observed in this work confirm previous results, but some minor products were not detected due to the small amount of material produced at the low pressures employed. Yields $(\mathrm{Y} \%)$ reported here are the sum of the mole percent of products after $10^{3}$ pulse irradiations. Only products that were formed in quantities large enough to be integrated reliably (usually $>0.1 \%$ of the total reaction mixture composition) are included in reported yields.

Reaction products found and their typical distributions are: cyclopentadiene and traces of pentadienes from cyclopentene; two different methylcyclopentadienes in equal amounts, and cyclopentadiene ( $<10 \%$ of the products) from 1-methylcyclopentene; acetylene and ethylene, ethane and propylene in the proportion 2:0.5:5 from cyclopropane; acetylene and ethylene, ethane, propane and propyne in the ratio 5:1:1:5 from propylene; and trans-2-butene, isobutene, cis-2-butene and 1-butene, and 1,3-butadiene in the proportion 2:3:3:1 from methylcyclopropane. Acetylene and ethylene, and cis-butene and 1-butene were not separated with the columns employed, hence their sum relative abundance is indicated in the product distributions above. Ethane and propane are not included in the yields from cyclopropane and propylene reactions, and methane, though formed 
in sufficient amounts with some reactants, was not included in the yields to avoid redundancy. Reaction products and yields for vinylcyclopropane and for cis- and trans-butene can be found in Refs. 9 and 10 respectively. Although some of other products may be formed by secondary reactions, or by photolysis of other products, this is of no concern to us in this paper. In all cases the reported yield is a good measure of the fraction of parent converted, which is the primary quantity of interest.

The products from cyclopentene, 1-methylcyclopentene, methylcyclopropane and vinylcyclopropane ${ }^{9}$ are all isomers of the parent or species having the same number of carbon atoms, with the exception of cyclopentadiene formed from 1-methylcyclopentene. Other products of higher or lower carbon number that might be formed by fragmentation and secondary reactions are present only in trace amounts. In these cases, the total product yield is a good measure of the fraction of parent converted. The trans- and cis-2-butene data shown in Figures 5 and 6 are obtained from observed conversions reported in Ref. 10, which should be consulted for details. In the cases of cyclopropane and propylene, the $\mathrm{C}_{2}$ products formed are indicative of $\mathrm{C}-\mathrm{C}$ bond breaking. Acetylene, ethylene and ethane are about $30 \%$ of the total products from cyclopropane, the remaining $70 \%$ being propylene, while the $\mathrm{C}_{2}$ 's were about $50 \%$ of total products from propylene. Methane, though formed in significant amounts, was not included in reported yields. Furthermore, ethane and propane are not included in yields reported in Table III and Figs. 2 and 3. Carbon atom balances show that the conversion of cyclopropane calculated by summing only the acetylene, ethylene and propylene yields is overestimated, but the error in the estimated conversion is only $5 \%$. For propylene, carbon atom balances indicate that the conversion calculated by summing acetylene, ethylene and propyne yields is underestimated by an amount equal to one third the methane yield. Typical methane yields are $17 \%$, so propylene conversion is only underestimated by $5 \%$. Since these estimates of the inaccuracy of calculated conversions for cyclopropane and propylene are about the same size as experimental error, no corrections were attempted. No attempt has been made to infer reaction mechanisms or primary photochemical processes in this work.

No products were observed with these five molecules for $10^{3}$ pulse irradiations with unfocused beams and fluences in the vicinity of $0.6 \mathrm{~J} / \mathrm{cm}^{2}$. 
Because of the strong dependence of reaction yields on fluence, it is important to employ the same fluence at all data points in a spectrum. The fluence was manipulated by varying the laser discharge voltage, or by inserting attenuators composed of polyethylene sheets. In these ways the same fluence was maintained over all the excitation lines. Due to the pulse to pulse variation and long term drift in laser output it is estimated that the fluences employed could be at variance by $\pm 5 \%$. This would give an uncertainty of $7-8 \%$ in the measured yields even with a conservative yield ( $Y \%)$-fluence $(\phi)$ dependence of $Y \propto \phi^{3 / 2}$ that is observed in some experiments with focused beams at high fluences. Considering other factors such as accuracy of GC analysis with small amounts of material and low conversion, the relative uncertainties in the yields reported could be $\pm 15 \%$.

\section{Yield comparisons}

Figures 2 through 9 show the multiple photon reaction yields for each species at several selected wavelengths superimposed on the corresponding linear absorption spectrum. Data were taken in the vicinity of prominent absorption bands except where limited by low laser gain. Literature assignments of the pumped bands are shown in Table I, and the maximum yields observed are reported in Table III.

Table I Pumped modes, integrated cross sections and low frequency fundamentals

\begin{tabular}{|c|c|c|c|c|}
\hline & $\begin{array}{l}\text { Observed } p \\
\text { and literati }\end{array}$ & $\begin{array}{l}\text { osition of modes }{ }^{1} \\
\text { ure assignments }\end{array}$ & $\begin{array}{l}\text { Integrated } \\
\text { absorption } \\
\text { cross-sections } \\
\left(10^{-18} \mathrm{~cm} / \text { molecule }\right)\end{array}$ & Refs. \\
\hline \multirow[t]{2}{*}{ Cyclopentene } & $\frac{1048}{1037} \mathrm{~cm}^{-1}$ & $\begin{array}{l}v_{30}, \alpha-\mathrm{CH}_{2} \text { rock } \\
v_{24}, \mathrm{~B}_{1} \text { ring mode }\end{array}$ & 1.4 & 28 \\
\hline & $\begin{array}{l}390 \\
127\end{array}$ & $\begin{array}{l}v_{17}, \mathrm{~A}_{2} \mathrm{C}=\mathrm{C} \text { torsion } \\
v_{33}, \mathrm{~B}_{2} \text { ring puckering }\end{array}$ & & \\
\hline \multirow[t]{3}{*}{$\begin{array}{l}\text { 1-methyl- } \\
\text { cyclopentene }\end{array}$} & $\underline{\underline{1002}}$ & $\begin{array}{l}\beta-\mathrm{CH}_{2} \text { twisting } \\
\beta-\mathrm{CH}_{2} \text { rocking }\end{array}$ & $\left.\begin{array}{l}0.78 \\
0.83\end{array}\right\} 1.6$ & 29 \\
\hline & $\begin{array}{l}432 \\
317 \\
228\end{array}$ & $\begin{array}{l}\mathrm{C}=\mathrm{C} \text { torsion } \\
\mathrm{C}-\mathrm{CH}_{3} \text { in-plane bending } \\
\mathrm{C}-\mathrm{CH}_{3} \text {, out-of-plane } \\
\text { bending }\end{array}$ & & \\
\hline & $\begin{array}{l}170 \\
104\end{array}$ & $\begin{array}{l}\text { methyl torsion } \\
\text { ring puckering }\end{array}$ & & \\
\hline
\end{tabular}


Table I (continued)

\begin{tabular}{|c|c|c|c|c|}
\hline & $\begin{array}{l}\text { Observe } \\
\text { and lite }\end{array}$ & $\begin{array}{l}\text { osition of modes } \\
\text { re assignments }\end{array}$ & $\begin{array}{l}\text { Integrated } \\
\text { absorption } \\
\text { cross-sections } \\
\left(10^{-18} \mathrm{~cm} / \text { molecule }\right)\end{array}$ & Refs. \\
\hline \multirow[t]{2}{*}{$\begin{array}{l}\text { Vinyl- } \\
\text { cyclopropane }\end{array}$} & $\begin{array}{l}\frac{941}{903} \\
985\end{array}$ & $\begin{array}{l}\text { ring deformation } \\
=\mathrm{C}(-\mathrm{H})_{2} \text { out-of-plane wag } \\
\text { ethylenic } \mathrm{CH} \text { bending }\end{array}$ & $\begin{array}{l}4.7 \\
g\end{array}$ & \multirow[t]{2}{*}{9,24} \\
\hline & $\begin{array}{l}425 \\
310(2) \\
75\end{array}$ & $\begin{array}{l}\} \mathrm{C}-\mathrm{C}-\mathrm{C}+\text { ring bends } \\
\text { hindered rotor }\end{array}$ & & \\
\hline Cyclopropane & $\underline{1028}$ & $v_{10}, \mathrm{E}^{\prime}$ ring deformation 2 & 2.7 & 30 \\
\hline Propylene & $\begin{array}{l}990 \\
\frac{920}{912} \\
578 \\
427 \\
174\end{array}$ & $\begin{array}{l}v_{18}, \mathrm{~A}^{\prime \prime} \text { ethylenic } \mathrm{CH} \text { bending } \\
v_{13}, \mathrm{~A}^{\prime} \mathrm{C}-\mathrm{C}-\text { stretching } \\
v_{19}, \mathrm{~A}^{\prime \prime} \mathrm{CH} \mathrm{H}_{2} \text { bending } \\
v_{20}, \mathrm{~A}^{\prime \prime} \mathrm{C}=\mathrm{C} \text { twisting } \\
v_{14}, \mathrm{~A}^{\prime} \mathrm{C}-\mathrm{C}=\mathrm{C} \text { bending } \\
v_{21}, \text { methyl torsion }\end{array}$ & \} 7.6 & 31 \\
\hline $\begin{array}{l}\text { Methyl- } \\
\text { cyclopropane }\end{array}$ & $\begin{array}{l}\frac{1021}{985} \\
931 \\
349 \\
291 \\
225\end{array}$ & $\begin{array}{l}v_{11}, \mathrm{~A}^{\prime} \mathrm{C}-\mathrm{C} \text { ring } \\
v_{26}, \mathrm{~A}^{\prime \prime} \beta-\mathrm{CCH} \text { ring } \\
v_{14}, \mathrm{~A}^{\prime} \beta-\mathrm{CCH} \text { ring } \\
\left.v_{17}, \mathrm{~A}^{\prime}\right\} \mathrm{C}-\mathrm{CH}_{3} \text { skeletal } \\
\left.v_{29}, \mathrm{~A}^{\prime \prime}\right\} \text { bending } \\
v_{30}, \text { methyl torsion }\end{array}$ & 2.0 & 32,37 \\
\hline cis-2-butene & $\begin{array}{l}\frac{970}{575} \\
396 \\
258 \\
290 \\
290\end{array}$ & 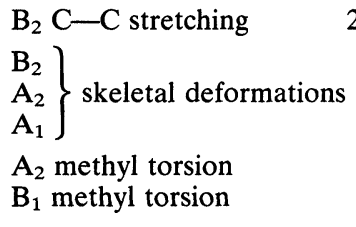 & 2.0 & 38 \\
\hline trans-2-butene & $\begin{array}{l}\frac{973}{964} \\
501 \\
290 \\
240 \\
210 \\
210\end{array}$ & 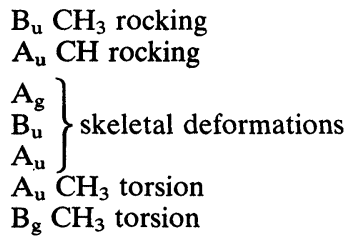 & \} 8.0 & 38 \\
\hline
\end{tabular}

${ }^{1}$ Underlined are modes for which integrated cross-sections are shown.

Large differences in reaction yields, and in the wavelength dependence of yields are apparent in Figures 2 through 9. Some of the salient features of these data are pointed out in the remainder of this section.

Cyclopropane is the most strongly bottlenecked case, with a maxi- 
Table II Unimolecular reactions and Arrhenius parameters

\begin{tabular}{lllcc}
\hline & & $\log \left[\mathrm{A}\left(\mathrm{sec}^{-1}\right)\right]$ & $\begin{array}{l}\mathrm{E}_{\mathrm{a}} \\
\mathrm{kcal} / \mathrm{mol}\end{array}$ & Ref. \\
\hline Cyclopropane & $\rightarrow$ propylene & 15.2 & 65 & $\mathrm{a}$ \\
& $\rightarrow \mathrm{CH}_{2}=\mathrm{CH}_{2}+: \mathrm{CH}_{2}$ & 15 & $\sim 100$ & \\
Propylene & $\rightarrow \mathrm{CH}_{2}=\mathrm{CHCH}_{2} \cdot+\mathrm{H} \cdot$ & 15.3 & 89.2 & $\mathrm{~b}$ \\
& $\rightarrow \mathrm{CH}_{2}=\mathrm{CH}_{2}+: \mathrm{CH}_{2}$ & 15.3 & $\sim 100$ & \\
Methyl- & $\rightarrow$ but-2-ene (cis \& trans) & 15.4 & 65 & $\mathrm{c}$ \\
cyclopropane & $\rightarrow$ but-1-ene & 14.4 & 60.5 & \\
& $\rightarrow$ isobutene & 14.6 & 66 & $\mathrm{~d}$ \\
Cyclopentene & $\rightarrow$ cyclopentadiene $+\mathrm{H}_{2}$ & 12.8 & 57.7 & $\mathrm{e}$ \\
Methyl- & $\rightarrow$ methylcyclopentadiene & 13.4 & 60 & \\
cyclopentene & + H & 13.6 & 49.7 & $\mathrm{f}$ \\
Vinyl- & $\rightarrow$ cyclopentene & 14.4 & 57.3 & \\
cyclopropane & $\rightarrow$ 1,4-pentadiene & 13.9 & 56.2 & \\
& $\rightarrow$ cis 1,3-pentadiene & 13.0 & 53.6 & \\
cis-2-butene & $\rightarrow$ trans 1,3-pentadiene & 13.4 & 61.6 & $\mathrm{~g}$ \\
\hline
\end{tabular}

${ }^{a}$ T. S. Chambers and G. B. Kistiakowsky, J. Am. Chem. Soc. 56, 399 (1934).

${ }^{b}$ H. E. O'Neal and S. W. Benson, "Kinetic data on gas phase unimolecular reactions," National Bureau of Standards NSRDS-NBS 21, 1970.

${ }^{c}$ D. W. Placzek and B. S. Rabinovitch, J. Chem. Phys. 69, 2141 (1965). J. W. Moore and R. J. Pearson, "Kinetics and mechanisms," 3rd ed., John Wiley and Sons Inc. (1981), p. 214.

d D. A. Knecht, J. Am. Chem. Soc. 95, 7933 (1973).

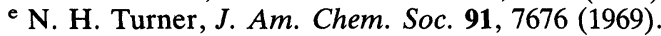

${ }^{f}$ C. A. Wellington, J. Phys. Chem. 66, 1671 (1962).

g B. S. Rabinovitch and K. W. Michel, J. Am. Chem. Soc. 81, 5065 (1959).

mum yield of only $2.2 \%$ per $10^{3}$ pulses at $0.43 \mathrm{~J} / \mathrm{cm}^{2}\left(\sim 110 \mathrm{~J} / \mathrm{cm}^{2}\right.$ at beam waist). Its isomer, propylene, reacts much more easily, with a maximum yield about ten times greater. Propylene has interesting structure in its yield spectrum in the vicinity of $960 \mathrm{~cm}^{-1}$, a region which is a superposition of the $\mathrm{R}$-branches of the strong $\mathrm{CH}_{2}$ bending mode centered at $912 \mathrm{~cm}^{-1}$ and a weaker $\mathrm{C}-\mathrm{C}$ stretching mode at $920 \mathrm{~cm}^{-1}$, and where there is no corresponding maximum in the linear IR spectrum. It is interesting that the generally inefficient R-branch irradiations resulted in larger maximum yield than the peak of cyclopropane, and the larger cyclopentene molecule.

Cyclopentene exhibits a strong bottleneck, since the product yields are comparable to those from the isomeric vinylcyclopropane which 
Table III Peak observed yields ${ }^{\mathrm{a}}(Y \%)$

\begin{tabular}{lclll}
\hline & $v, \mathrm{~cm}^{-1}$ & $\phi, \mathrm{j} / \mathrm{cm}^{2 \mathrm{~b}}$ & $\begin{array}{l}Y \% / \text { no. of } \\
\text { pulses }\end{array}$ & $E_{t}{ }^{\mathrm{f}}, 10^{3} \mathrm{~cm}^{-1}$ \\
\hline Cyclopentene & 1031.47 & $0.64(\sim 160)$ & $16.4 / 10^{3}$ & 3.87 \\
& & {$[0.46]$} & {$[7.9]^{\mathrm{c}}$} & \\
1-methylcyclopentene & 988.65 & $0.46(\sim 115)$ & $33.6 / 10^{3}$ & 2.23 \\
Vinylcyclopropane & 924.97 & $(\sim 2.5)$ & $\sim 19 / 100$ & 2.77 \\
Cyclopropane & 1023.19 & $0.43(\sim 110)$ & $2.2 / 10^{3}$ & 7.0 \\
Methylcyclopropane & 1021.06 & $0.43(\sim 110)$ & $47.2 / 10^{3}$ & 3.5 \\
Propylene & 922.92 & $0.43(\sim 110)$ & $22 / 10^{3}$ & 5.0 \\
cis-2-butene & 957.8 & $0.45(\sim 115)$ & $33.6 / 500$ & 2.87 \\
trans-2-butene & 957.8 & $0.45(\sim 115)$ & $82.6 / 500$ & 2.5 \\
\hline
\end{tabular}

${ }^{a}$ Mole $\%$ of products in the reaction mixture after irradiation.

${ }^{b}$ Average pulse fluences before focussing (i.e., based on the aperture cross section area). Numbers in brackets are the estimated maximum fluences at focus inside the reaction cell. For vinylcyclopropane, the maximum fluence of $2.5 \mathrm{j} / \mathrm{cm}^{-2}$ exists at the front window as the $5 \mathrm{~cm} * 2.5 \mathrm{~cm}$ (I.D.) cell was placed beyond the focal region.

${ }^{c}$ Scaled to $0.464 \mathrm{j} / \mathrm{cm}^{2}$ using relation $Y \propto \phi^{2.2}$ found experimentally, ${ }^{8}$ for comparison with 1-methylcyclopentene yield.

${ }^{d}$ Data taken from Farneth et al.$^{9}$

e Data from Ref. (10).

${ }^{\text {f }}$ Excitation energy to reach a $\rho(\mathrm{E})$ of 100 states $/ \mathrm{cm}^{-1}$.

were obtained with unfocused radiation at only about $2.5 \mathrm{~J} / \mathrm{cm}^{2}$, between one and two orders of magnitude smaller than the estimated fluence at the beam waist in cyclopentene. Furthermore, cyclopentene yields are smaller than the peak yields from the smaller propylene, methylcyclopropane and 2-butene molecules. While 1-methylcyclopentene pumps more easily than cyclopentene in the vicinity of its $1000 \mathrm{~cm}^{-1}$ absorption feature, it is interesting that it reacts with more difficulty than the smaller molecules, trans-2-butene and vinylcyclopropane.

Evidence of yield red-shifts in the vicinity of absorption maxima is readily apparent in cyclopentene, vinylcyclopropane, cis-2-butene and 1-methylcyclopentene. For cyclopropane and methylcyclopropane, yields correlate very strongly with Q-branch peaks. In contrast, the yield from cyclopentene is a minimum at the $1048 \mathrm{~cm}^{-1} \mathrm{Q}$-branch, presumably indicating some difference in lower vibrational level excitation mechanism between cyclopentene and cyclopropane/ methylcyclopropane. The propylene Q-peaks at $912 \mathrm{~cm}^{-1}$ and 990 $\mathrm{cm}^{-1}$ could not be accessed because of small laser gain at these 


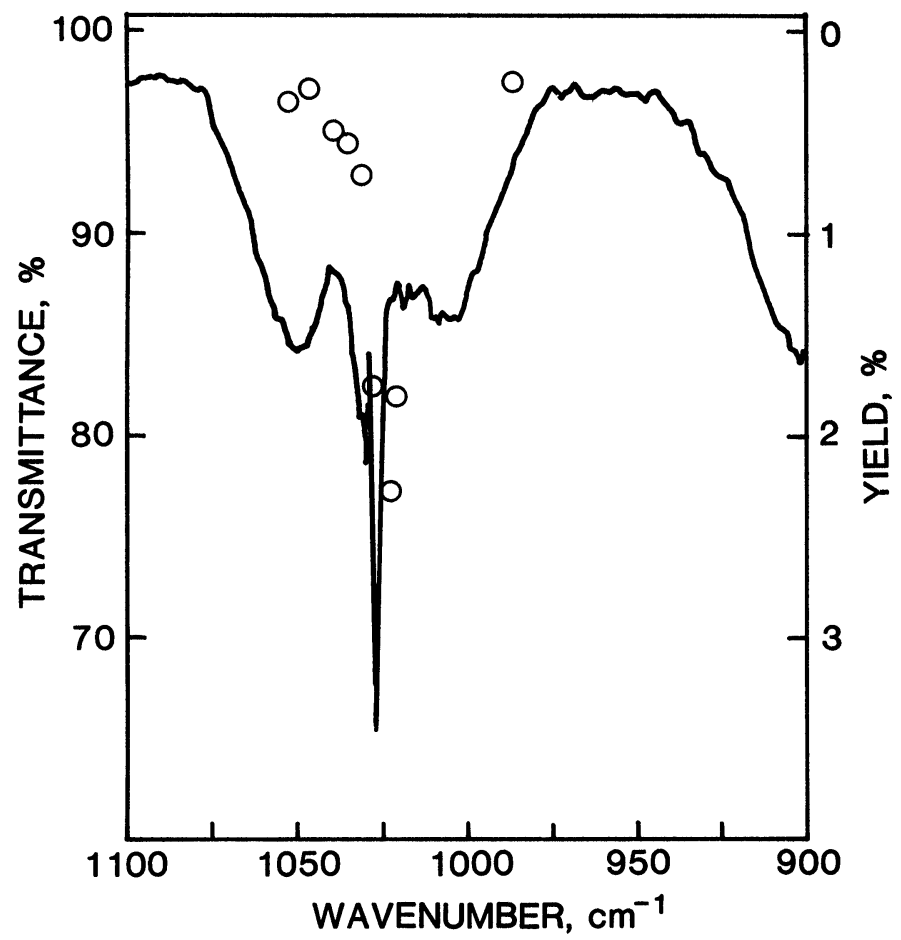

Figure 2 Solid line, infrared spectrum of cyclopropane, $p=10.65$ torr: $\circ$, product yield per $10^{3}$ pulses at $0.43 \mathrm{j} / \mathrm{cm}^{2}\left(\sim 110 \mathrm{j} / \mathrm{cm}^{2}\right.$ at focus) in 53 mtorr of neat gas.

wavenumbers. The absence of a red-shift in cyclopropane/ methylcyclopropane is surprising as the anharmonic shift of the first overtone from the fundamental in cyclopropane is estimated at $\sim 23 \mathrm{~cm}^{-130}$ for the ring deformation mode. In contrast, vinylcyclopropane, which exhibits a very facile MPE, has a distinct red-shift in its MPD yields.

\section{DISCUSSION}

In this section we first examine factors that are commonly acknowledged to affect MPD yields, then discuss whether or not the observed differences in reaction yields correlate with these factors. Factors to be 
considered are vibrational state density, linear absorption strength, the effect of internal rotors and where possible, the vibrational transitions involved.

Small reaction probabilities at high fluences $\left(\sim 100 \mathrm{~J} / \mathrm{cm}^{2}\right)$ can be interpreted as a reflection of the severity of anharmonic bottleneck effects to be overcome in lower discrete transitions. Energy mismatch between vibrational spacing and the laser frequency may be compensated by power broadening, vibrational-rotational interaction, multiphoton resonances at high intensities, anharmonic splittings of degenerate levels, and fortuitous anharmonic compensations., ${ }^{16-18}$ Once a molecule acquires sufficient vibrational energy, anharmonic coupling of pumped mode levels to a dense set of background levels

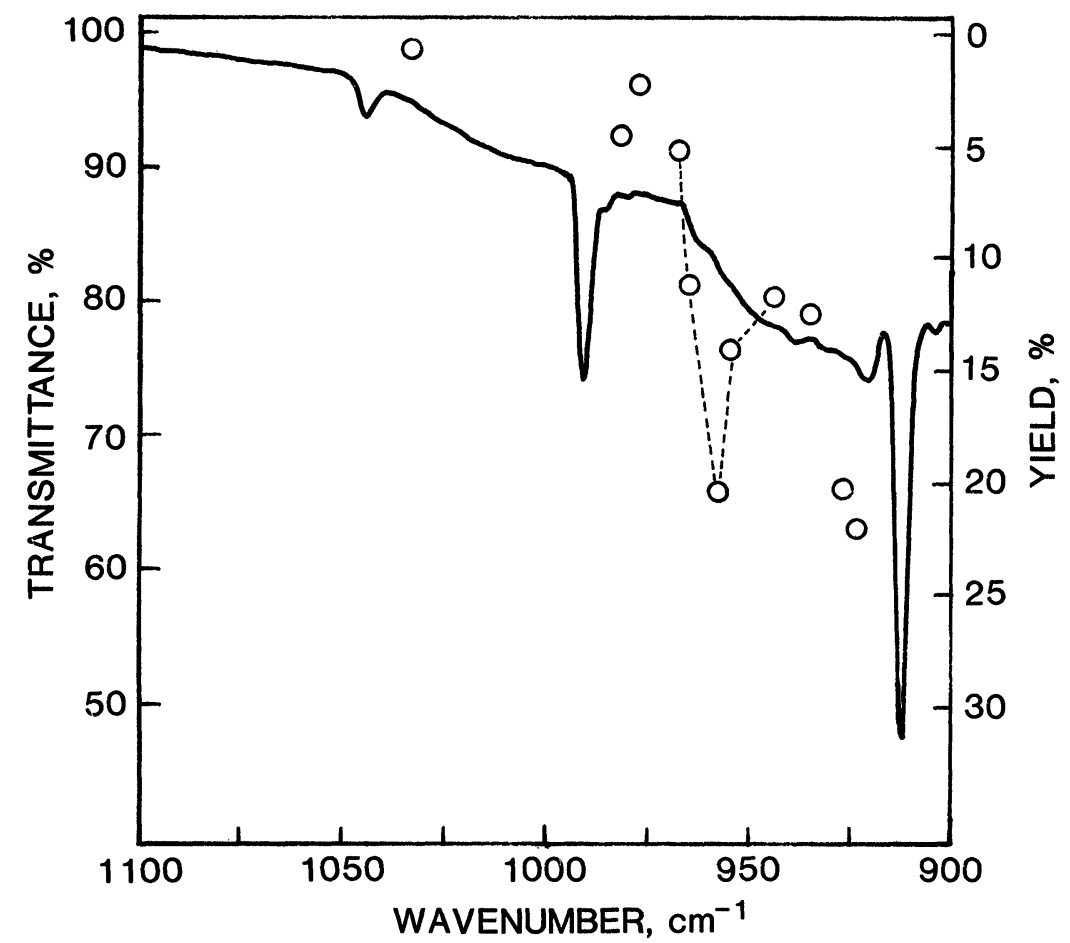

Figure 3 Solid line, infrared spectrum of propylene, $p=10.65$ torr: $\circ$, product yield per $10^{3}$ pulses at $0.43 \mathrm{j} / \mathrm{cm}^{2}\left(\sim 110 \mathrm{j} / \mathrm{cm}^{2}\right.$ at focus $)$ in 53 mtorr of neat gas. 


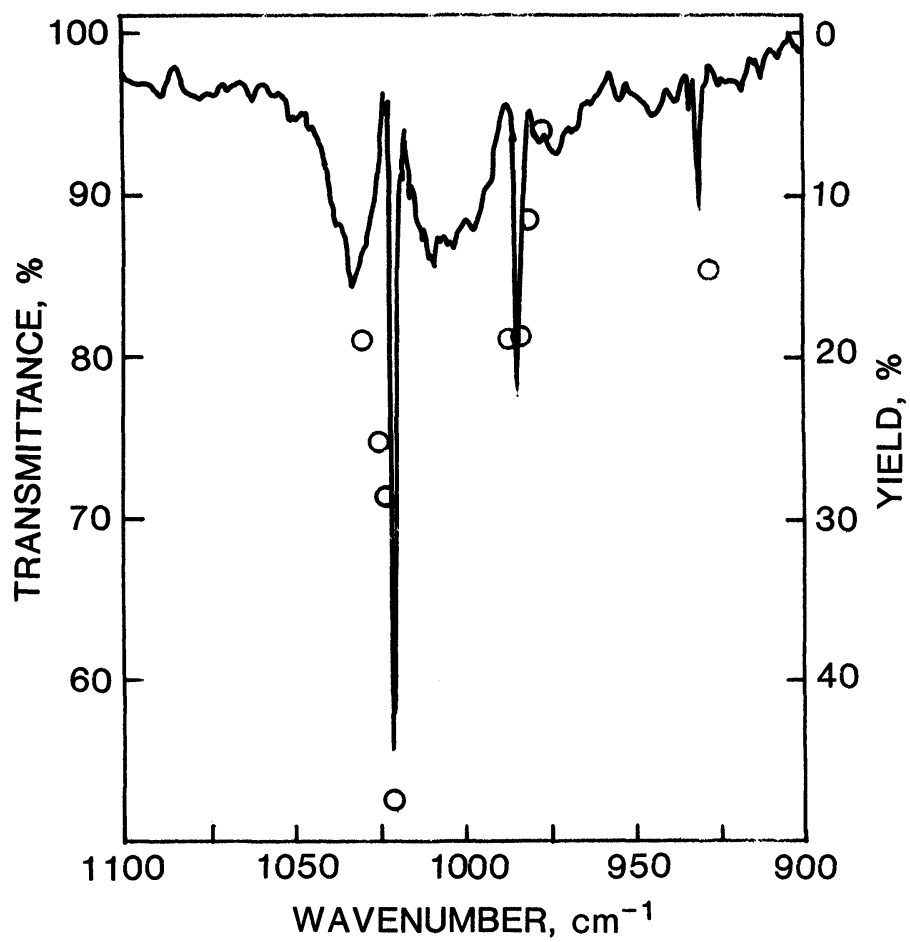

Figure 4 Solid line, infrared spectrum of methylcyclopropane, $p=10.65$ torr: $\odot$, product yield per $10^{3}$ pulses at $0.43 \mathrm{j} / \mathrm{cm}^{2}\left(\sim 110 \mathrm{j} / \mathrm{cm}^{2}\right.$ at focus $)$ in $53 \mathrm{mtorr}$ of neat gas.

can occur, leading to IVR of pumped mode excitation. It is generally accepted that the high density of states here forms a QC such that the resonance condition is always met and the absorption dynamics can be described by incoherent rate Eq. (19). Thus the number of transitions needed before the onset of QC can determine the ease or difficulty of MPE in a molecule. Studies on MPD of ethylchloride ${ }^{16}$ showed $3 \mu \mathrm{m}$ excitation to be more efficient than $10 \mu \mathrm{m}$ excitation, possibly reflecting the fact that fewer steps are needed to reach the QC with larger energy photons.

Vibrational density of states, $\rho(\mathrm{E})$, is known to be a key limiting factor for IVR, ${ }^{20}$ and the critical $\rho(\mathrm{E})$ for subnanosecond randomization of even abnormally well localized initial vibrational excitation is of the order of 1000 states per $\mathrm{cm}^{-1}$ or less. ${ }^{21}$ The threshold density of 
states for randomization is molecular as well as mode specific as it depends on the anharmonic coupling elements of the molecule. Studying relaxation from $\mathrm{C}-\mathrm{H}$ stretch fundamentals in several molecules, Stewart and $\mathrm{McDonald}{ }^{20}$ reported threshold densities to vary within the range of 5 to 50 states per $\mathrm{cm}^{-1}$ for the onset of IVR. We have chosen a fixed $\rho(\mathrm{E})$ of 100 states per $\mathrm{cm}^{-1}$ as a representative value of threshold state density. The excitation energy required to reach this value, $E_{t}$, is used as a guide in comparisons assessing the role of state densities. $E_{t}$ 's are listed in Table III along with the peak yields. We emphasize that $\rho(\mathrm{E})=100$ states per $\mathrm{cm}^{-1}$ is only chosen for convenience in making comparisons, and not to imply a firm value for the threshold vibrational state density. A lower bound for this value may be estimated using the condition $\rho(\mathrm{E})>1 / \Delta v_{1}$, for more than one vibrational level to be overlapped by the linewidth, $\Delta v_{1}$, of the laser. Taking the linewidth of our laser to be $\sim 0.03 \mathrm{~cm}^{-1}$ (as estimated in the Experimental section) gives a $\rho(\mathrm{E}) \sim 30$ states $/ \mathrm{cm}^{-1}$.

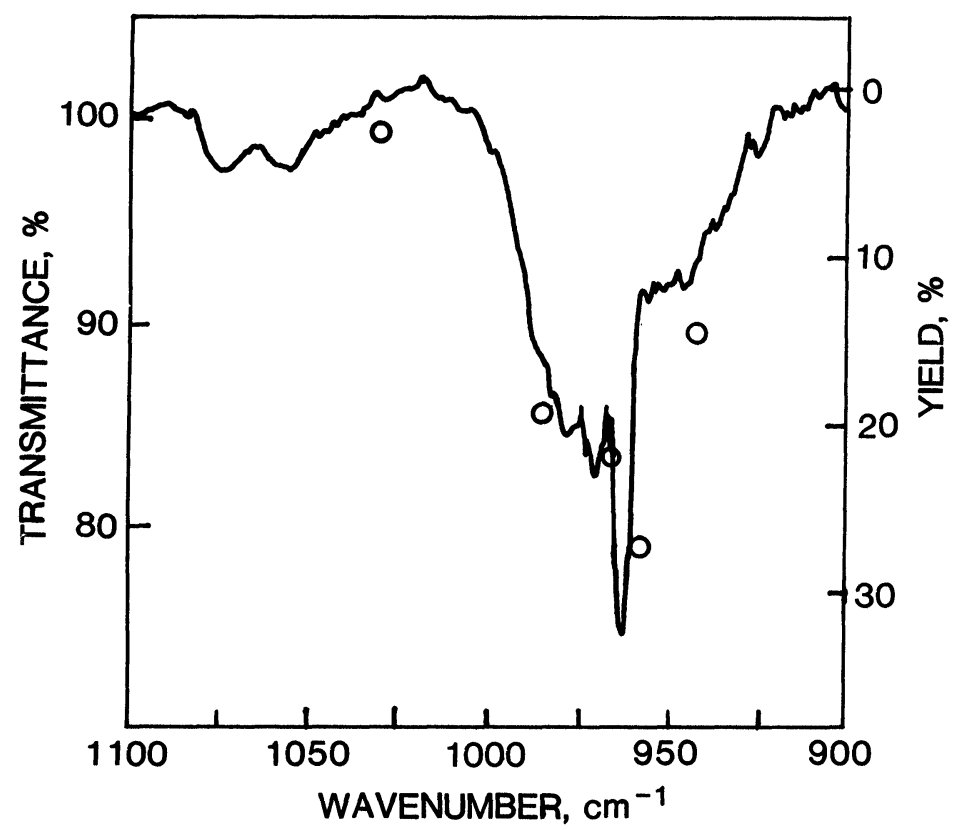

Figure 5 Solid line, infrared spectrum of trans-2-butene, $p=3$ torr: $\circ$, product yield per 100 pulses at $0.45 \mathrm{j} / \mathrm{cm}^{2}\left(\sim 114 \mathrm{j} / \mathrm{cm}^{2}\right.$ at focus) in 50 mtorr of neat gas. 


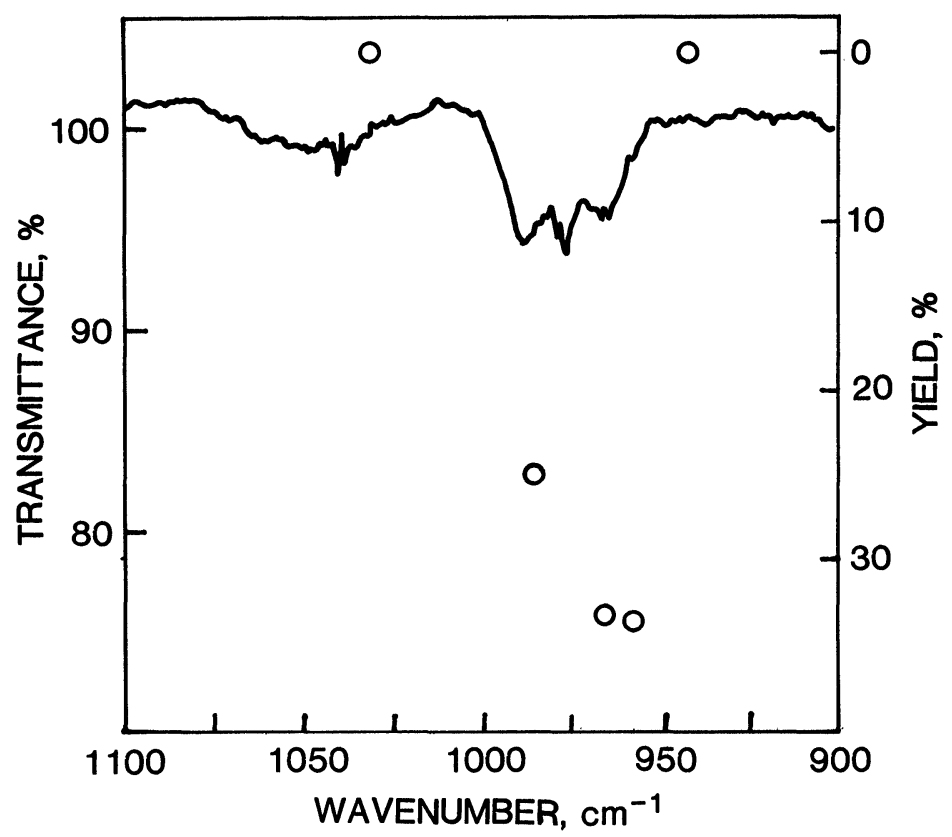

Figure 6 Solid line, infrared spectrum of cis-2-butene, $p=3$ torr: $\bigcirc$, product yield per 500 pulses at $0.45 \mathrm{j} / \mathrm{cm}^{2}\left(\sim 115 \mathrm{j} / \mathrm{cm}^{2}\right.$ at focus $)$ in 53 mtorr of neat gas.

Figure 10 shows the densities of vibrational states versus excitation above the ground level, calculated by direct state counting methods ${ }^{22}$ using the literature fundamental mode frequencies (see Table I for sources). All modes except the internal rotors were treated as harmonic oscillators. The internal rotor treatment employed is described in the Appendix. The dashed lines shown for propylene, vinylcyclopropane and trans-2-butene are state densities when the internal rotors are treated as harmonic oscillators and show the enhancement in $\rho(\mathrm{E})$ due to the degeneracies of the internal rotor levels.

Integrated linear absorption strengths, $\sigma$, of the pumped modes obtained by integrating the linear IR absorption bands, are shown in Table I, and significant differences can be seen in them. Larger $\sigma$ 's imply a larger fraction of ground state molecules interacting with the radiation and also greater power broadening of levels (or Rabi frequency). Table I also shows the infrared active transitions that overlap 
or are in close proximity to the pumped mode absorption band and, in addition, shows low frequency modes present in each species.

Unimolecular reaction threshold energies are listed in Table II. The threshold energy of the lowest reaction channel determines the number of photons required to reach the region of reactive states. In molecules with a discrete level excitation bottleneck this is not expected to be a critical parameter in determining the facility of MPD. Even so, apart from propylene and vinylcyclopropane, the differences in the lowest channel reaction threshold energies of these molecules are small. Thus, energetics can in most cases, be safely disregarded as a factor controlling variation in product yields.

Differences in state densities are seen to be significant even amongst the isomeric pairs (Figure 10). For instance, a density of 100 states/

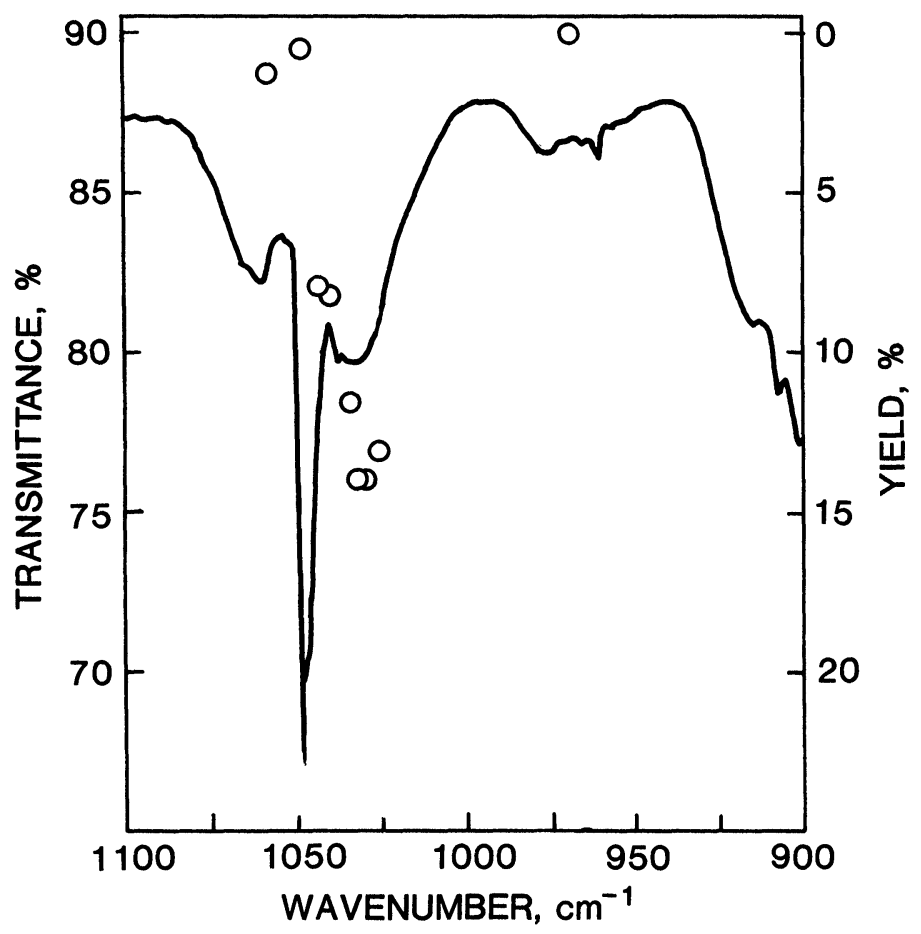

Figure 7 Solid line, infrared spectrum of cyclopentene, $p=10.65$ torr: $\odot$, product yield per $10^{3}$ pulses at $0.6 \mathrm{j} / \mathrm{cm}^{2}\left(\sim 160 \mathrm{j} / \mathrm{cm}^{2}\right.$ at focus) in 53 mtorr of neat gas. 


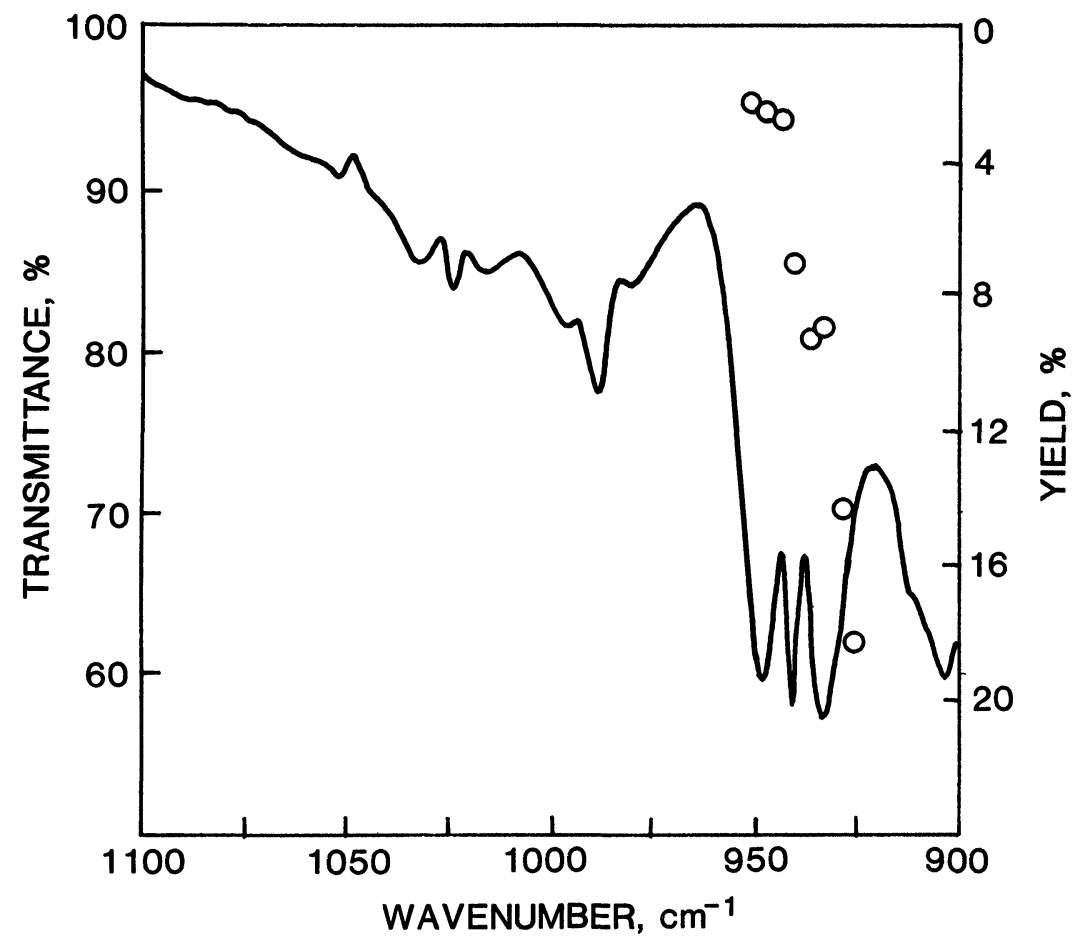

Figure 8 Solid line, infrared spectrum of vinylcyclopropane, $p=10.65$ torr: $\odot$, product yield per 100 pulses in 200 mtorr of neat gas. Maximum fluence of $2.5 \mathrm{j} / \mathrm{cm}^{2}$ occurring at the front window.

$\mathrm{cm}^{-1}$ is reached at an excitation energy of $\sim 5000 \mathrm{~cm}^{-1}$ in propylene as against an energy of $\sim 7000 \mathrm{~cm}^{-1}$ required in cyclopropane, indicating two fewer discrete level transitions are required for propylene than for cyclopropane. Cyclopropane requires above seven photons to be absorbed before 100 states $/ \mathrm{cm}^{-1}$ are reached, indicating ample opportunity for it to be bottlenecked. Significant differences in $\rho(E)$ are also seen in the isomeric pairs vinylcyclopropane-cyclopentene and cis-trans-2-butene-methylcyclopropane. It is evident in these comparisons that the isomer possessing a larger number of low frequency fundamentals, such as the small frequency internal rotation with its level degeneracies and accompanying skeletal bending modes (Table I), can have larger state densities significant enough to possibly lower the onset of QC and lead to more facile MPE. It is interesting to note 
that cis- and trans-2-butene, though smaller molecules (possessing fewer vibrational modes), have $\rho$ (E)'s greater than cyclopentene and comparable to vinylcyclopropane, presumably because of their two internal rotors.

The peak yield at $E_{t}$ data in Table III suggests that in some cases larger state densities may be responsible for easing the excitation bottleneck. For example, larger yields from methylcyclopropane and propylene than cyclopropane, and from methylcyclopentene and vinylcyclopropane than cyclopentene may be a consequence of larger state densities in the former pair. If state densities alone were responsible for observed trends in MPD yields, one would expect a good correlation between $(Y \%)$ and $\left(E_{t}\right)^{-1}$. A plot of these quantities using data from Table III (not shown) showed extensive scatter so that it was

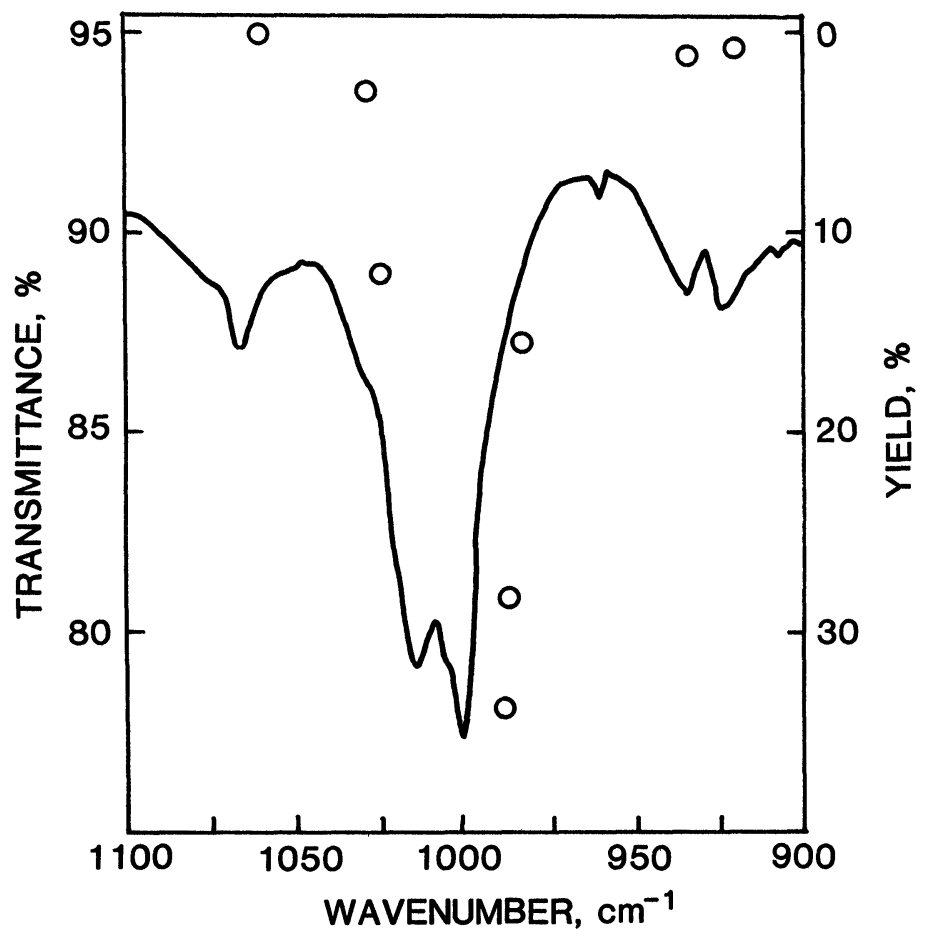

Figure 9 Solid line, infrared spectrum of 1-methylcyclopentene, $p=10.65$ torr: $\odot$, product yield per $10^{3}$ pulses at $0.46 \mathrm{j} / \mathrm{cm}^{2}\left(\sim 115 \mathrm{j} / \mathrm{cm}^{2}\right.$ at focus) in $53 \mathrm{mtorr}$ of neat gas. 


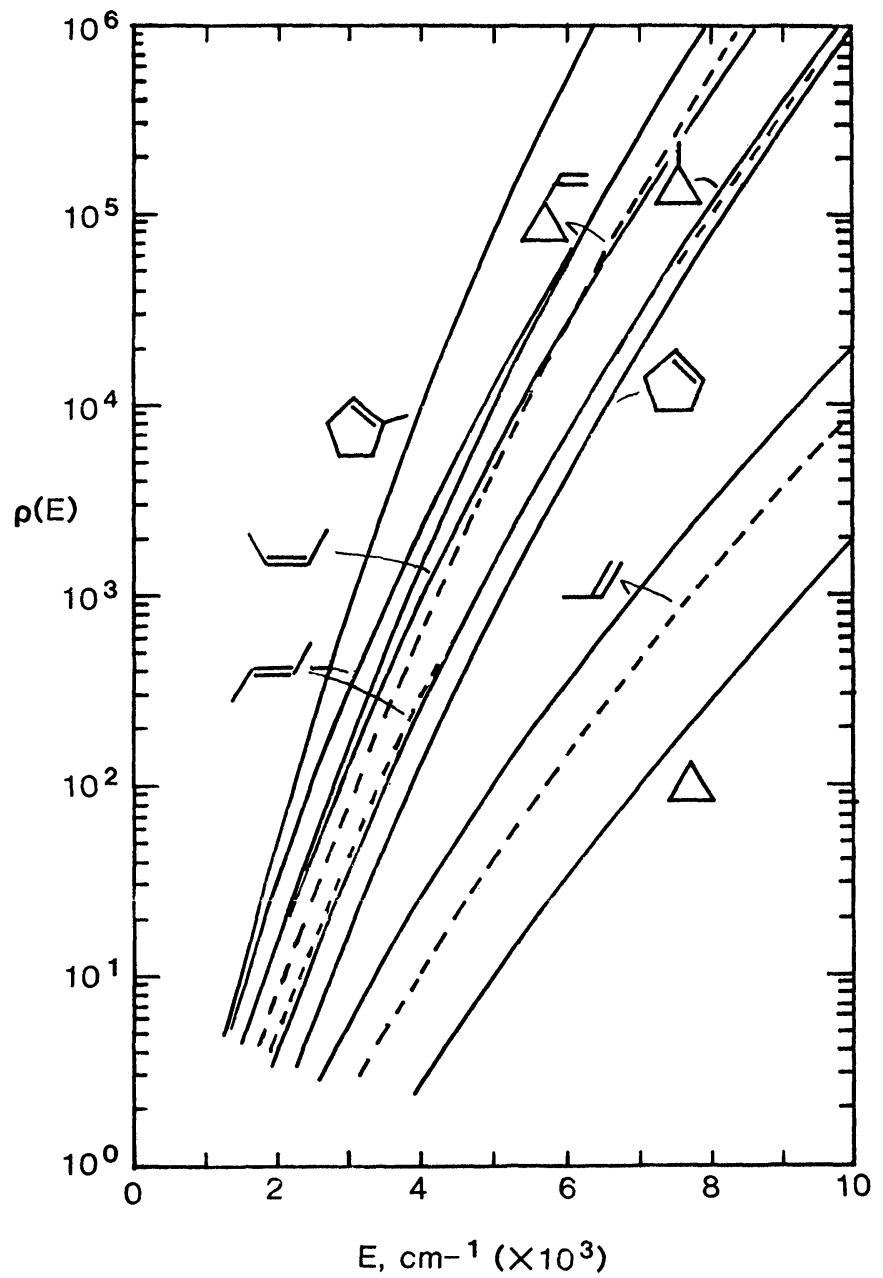

Figure 10 Vibrational state densities, $\rho(\mathrm{E})$, versus excitation energy, E, from exact count methods. Broken lines are when the internal rotation is treated as a harmonic oscillator with the torsion frequency.

not possible to establish such a correlation. For instance, 1methylcyclopentene is not as readily pumped as vinylcyclopropane, even though it has higher $\rho(\mathrm{E})$ and may require as few as two discrete level transitions.

Considering the molecular pairs cyclopentene-1-methylcyclopen- 
tene, and cyclopropane-methylcyclopropane, it can be seen that similar modes with comparable absorption strengths (Table I) were irradiated in each pair, and also that the Arrhenius parameters are very similar (Table II). Thus the differences in $\rho$ (E)'s could account for the differences in the reaction yields in these pairs. Larger $\rho(\mathrm{E})$ 's in the methyl substituted molecules as opposed to their counterparts reflect their larger size and also the fact that some of the modes due to the additional methyl rotor are low frequency motions such as methyl torsion, and $\mathrm{C}-\mathrm{CH}_{3}$ in-plane and out-of-plane bending motions (Table I).

Comparing molecules of equal size, vinylcyclopropane and propylene pump much easier than their isomeric counterparts cyclopentene and cyclopropane respectively. This enhancement in yields could be partly ascribed to the presence of methyl rotors that raise the $\rho(\mathrm{E})$, Figure 10, as noted earlier. Yield disparities in these two pairs must also be reflecting the differences in $\sigma$ 's which are three times larger in vinylcyclopropane and propylene as opposed to their counterparts (Table I). In addition, other IR active modes are present in close proximity to the pumped modes in vinylcyclopropane (Figure 8 ) and propylene (Figure 3 ). It has been pointed out that closely spaced modes can have an effect similar to the anharmonic splitting of degenerate modes in more symmetric molecules by forming a band of excited state energy levels that can aid MPE by providing resonant transitions for excitation in the discrete level region $(16,23)$. Lower reaction threshold energy in vinylcyclopropane (Table II) could also be aiding its MPD process.

Larger yields in trans-2-butene when compared to cis-2-butene may be reflecting its stronger absorption band, with a four times larger $\sigma$, both having comparable $\rho(\mathrm{E})$ 's. This absorption band is a superposition of two IR active modes (Table I). Since cis-2-butene and methylcyclopropane have equal $\sigma$ 's, the marginal enhancement of MPD yield in cis-2-butene may be attributed to its larger $\rho(\mathrm{E})$.

Although peak MPD yields are influenced by $\rho(\mathrm{E})$ and $\sigma$, there are prominent differences in yield vs. wavelength behavior that show the dominant role played by the individual discrete level patterns in the MPD process in these molecules. For instance, methylcyclopropane has only a small advantage in density of states and absorption cross section over cyclopentene, but the reaction yields and spectra are substantially different (Figures 4 and 7), indicating the differences in 
the lower level excitation mechanisms and structure in the two molecules. The large red shift in cyclopentene is apparently not present in methylcyclopropane (see the data on the red side of the weaker mode at $981 \mathrm{~cm}^{-1}$ in Figure 4). Preliminary opto-acoustic measurements of multiple photon absorption (MPA) in cyclopentene show that the MPA spectrum (measured at $0.47 \mathrm{~J} / \mathrm{cm}^{2}$ with collimated beam and at $\sim 115 \mathrm{~J} / \mathrm{cm}^{2}$ employing focused beam), in contrast to its MPD yield versus wavelength behavior, mimics the linear IR band closely with a minor red shift of about $2-3 \mathrm{~cm}^{-1}$ and some broadening at the Rbranch. These observations suggest that most cyclopentene molecules absorbing the radiation are bottlenecked, presumably before reaching the QC, and the large red shift in MPD yields is reflecting either the excitation mechanisms, such as due to multiphoton resonances and PQR rotational compensations, or some fortuitous discrete level pattern in cyclopentene leading a relatively larger fraction of molecules into the QC at these red shifted laser wavelengths. In comparison, the presence of an internal rotor and other IR active modes close to the pumped mode (at 981 and $931 \mathrm{~cm}^{-1}$ ) in methylcyclopropane could be providing it additional pathways and resonant levels in the discrete region leading to easier pumping and less red-shifting.

It is instructive to take a closer look at the pair of cyclopropane and propylene, the former exhibiting a severe bottleneck. An attempt was made to compare the threshold fluences for MPD in these molecules to determine if the larger yields in propylene are merely due to a larger fraction of ground state molecules interacting with the laser radiation. Threshold fluence can be a good criterion for comparing the ease of excitation through the vibrational manifold and hence the ease of MPD in molecules as it eliminates the differences in the fraction of molecules interacting with the laser and the differences in the reaction rates above the dissociation threshold. A log-log plot of yield vs. fluence at the laser lines which resulted in maximum yields are shown in Figure 11. Up to 4000 pulses were employed at the lowest yields and the yields are close to the sensitivity limit of the gas chromatograph. Within the accuracy of the data, threshold fluences are seen to be similar, approximately $10 \mathrm{~J} / \mathrm{cm}^{2}$ in both the molecules. The absolute value of $10 \mathrm{~J} / \mathrm{cm}^{2}$ is approximate due to the experimental constraints and should be taken as an upper bound only. Though the Rabi frequency, $\omega_{\mathrm{R}}=\mu \mathrm{E} / \mathrm{h}$ ( $\mu$ is the transition dipole moment proportional to $\sigma$ ), is three times larger in propylene, estimated to $b e \approx 3 \mathrm{~cm}^{-1}$ for 10 


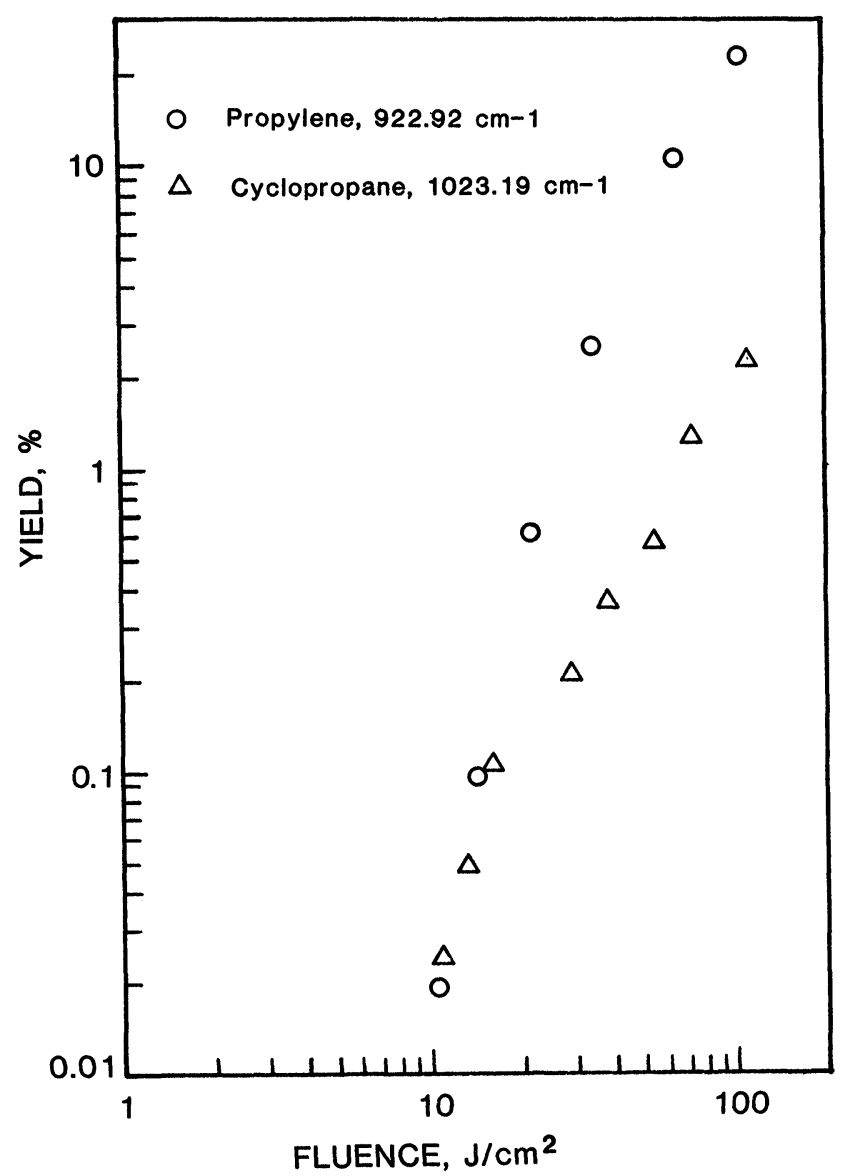

Figure 11 Product yields, per $10^{3}$ pulses, versus pulse fluence at the focal region, $p=53$ mtorr.

$\mathrm{j} / \mathrm{cm}^{2}$ pulse, it is not sufficient to compensate for the anharmonicity of the $\mathrm{C}-\mathrm{C}$ stretch mode $\left(v_{13}\right)$ at $920 \mathrm{~cm}^{-1}$, which is approximately 12 $\mathrm{cm}^{-1}$ (determined from the relation $\delta=v_{13}{ }^{2} / 2 \mathrm{D}$, D is taken as 100 $\mathrm{kcal} / \mathrm{mol}$ for the dissociation energy of the $\mathrm{C}-\mathrm{C}$ bond). After taking into consideration the facts that the activation energy of the lowest channel in propylene (the allyl $\mathrm{C}-\mathrm{H}$ cleavage) is about $24 \mathrm{kcal} / \mathrm{mole}$ higher (i.e., eight additional $\mathrm{CO}_{2}$ laser photons) than the lowest 
channel in cyclopropane, and that the laser was tuned to the blue side of the linear absorption peak in propylene, it appears that propylene is a more efficient absorber of $10 \mu \mathrm{m}$ radiation and its vibrational manifold has less of a bottleneck possibly indicating an earlier onset of $\mathrm{QC}$ due to its larger $\rho(\mathrm{E})$ and/or due to the presence of other modes in close proximity of the pumped mode as noted earlier. Threshold intensities were found to be larger on the blue side of the linear band in $\mathrm{SF}_{6} \cdot{ }^{33}$

The sharp structure observed at $957.8 \mathrm{~cm}^{-1}$ in propylene MPD yields does not have a corresponding feature in the linear IR spectrum. Such additional resonances were found in ethylchloride, ${ }^{16}$ probed with a continuously tunable $3.3 \mu \mathrm{m}$ source. These were correlated to strong features in the first and second overtone spectra, indicating as possible 2- and 3-photon resonances. Also, resolved structures in the MPD yields were observed in $\mathrm{CF}_{3} \mathrm{Br}^{34}$ and $\mathrm{CF}_{3} \mathrm{I},{ }^{35}$ under molecular beam conditions which were assigned as various multiphoton resonances, based on their peak positions. In the same spirit we list some possible causes for the resonance observed in propylene. Though there is no absorption feature at $\sim 1916 \mathrm{~cm}^{-1}$ in the low signal IR spectrum of propylene, for a possible two photon process, the position matches with the possible combination band involving the fundamentals $v_{13}$ $\left(920.4 \mathrm{~cm}^{-1}\right)$ and $v_{18}\left(990.0 \mathrm{~cm}^{-1}\right)$. A 3-photon resonance (to $\sim 2874$ $\mathrm{cm}^{-1}$ ) matches the position of the sharp Q-peak of $v_{5}$ at $\sim 2870 \mathrm{~cm}^{-1}$ and falls within the envelope of the overlapping strong absorption bands in $2850-3150 \mathrm{~cm}^{-1}$ range. And finally there appears to be a very weak absorption feature embedded at $\sim 962 \mathrm{~cm}^{-1}$ in the linear IR spectrum of propylene. FTIR spectrum taken at a resolution of 0.24 $\mathrm{cm}^{-1}$ resolves the rotational structure of the R-branches but fails to resolve this feature. If this feature exists, its position matches with $2 v_{20}-v_{21}$ transition, which is a transition from the first excited level of the methyl torsion to the overtone of $\mathrm{C}=\mathrm{CH}_{2}$ twisting. The low frequency methyl torsion mode has significant population in its first and second excited levels as evidenced by the Boltzmann factors of 0.395 and 0.173 respectively at $300^{\circ} \mathrm{K} .{ }^{27}$

Currently, optoacoustic measurements of MPA in these molecules are underway. Optoacoustic detection measuring average excitation is a sensitive and convenient technique that may provide further insights on the factors affecting excitation in the discrete level region and the resonances occurring there. 


\section{CONCLUSION}

The differences in reaction yields in these molecules under similar experimental conditions can be interpreted as a reflection of the effects of vibrational state density, linear absorption strength, and the discrete level patterns, on the degree of lower level excitation bottleneck. The data show these parameters at play to varying degrees in several not dissimilar molecules. No simple correlation with these factors separately or in combination is apparent. The comparisons presented here clearly show the complexity of infrared multiple photon photochemistry.

Vibrational states density and linear absorption strength clearly play a role in MPD. While some of the observations reported here can be explained by these factors, others cannot. Prominent among the latter are the enormous differences in yield at the $\mathrm{Q}$ branches of the 1048 $\mathrm{cm}^{-1}$ band in the cyclopentene, and the $1021 \mathrm{~cm}^{-1}$ band in methylcyclopropane, and the MPD feature at $958 \mathrm{~cm}^{-1}$ in propylene. These observations, as well as other disparities in yield vs. wavelength behavior must be attributed to specifics of the discrete level excitation mechanisms that are at play, and to the individual patterns of the lower levels. Spectroscopy of the excited vibrational levels will be necessary to unambiguously sort out these mechanisms.

In comparison in pairs of molecules it is seen that an internal rotor, which gives rise to a low frequency torsional mode with its level degeneracies and to the associated low frequency skeletal bending vibrations, can considerably increase the vibrational densities in small or moderate sized molecules. This we suggest forms part of the reason for the strong bottleneck in cyclopropane and cyclopentene to be diminished, for instance, in propylene and vinylcyclopropane respectively.

\section{Acknowledgement}

The assistance of the National Science Foundation, Grant No. ENG-7911586, in purchasing the TEA $\mathrm{CO}_{2}$ laser is gratefully acknowledged. Support of the experimental program was from the National Science Foundation under Grant No. CPE-8023180.

\section{References}

1. N. Bloembergen, C. D. Cantrell and D. M. Larsen, in Proceedings of the Conference on Tunable Lasers and Applications (Loen, Norway), edited by A. Mooradian, T. Jaeger and P. Stokseth (Springer, Berlin, 1976), p. 162. 
2. S. Mukamel and J. Jortner, Chem. Phys. Lett. 40,150 (1976) and J. Chem. Phys. 65, 5204 (1976).

3. D. M. Larson, Opt. Commun. 19, 404 (1976).

4. H. W. Galbraith and J. R. Ackerhalt, in Laser-Induced Chemical Processes, edited by J. I. Steinfeld (Plenum, New York, 1981), p. 1.

5. D. M. Larsen and N. Bloembergen, Opt. Commun. 17, 254 (1976).

6. T. B. Simpson, J. G. Black, I. Burak, E. Yablonovitch and N. Bloembergen, J. Chem. Phys. 83, 628 (1985).

7. R. D. McAlpine, D. K. Evans and F. K. McClusky, J. Chem. Phys. 73, 1153 (1980).

8. J. O. Shoemaker and R. W. Carr, Jr., J. Phys. Chem. 88, 605 (1984).

9. W. E. Farneth, M. W. Thomsen, N. L. Schultz and M. A. Davies, J. Am. Chem. Soc. 103, 1004 (1981).

10. J. R. Guckert, Ph.D. Thesis, University of Minnesota, 1981; J. R. Guckert and R. W. Carr, J. Phys. Chem. 90, 5679 (1986).

11. J. O. Shoemaker and R. W. Carr, Jr., Rev. Sci. Instrum. 53, 1086 (1982).

12. R. B. Ball and A. Kaldor, J. Chem. Phys. 70, 4027 (1979).

13. M. L. Lesiecki and W. A. Guillory, J. Chem. Phys. 66, 4317 (1977).

14. Z. Karny and R. N. Zare, Chem. Phys. 23, 321 (1977).

15. W. Braun and W. Tsang, Chem. Phys. Lett. 44, 354 (1976).

16. H. L. Dai, A. H. Kung and C. B. Moore, J. Chem. Phys. 73(12), 6124 (1980).

17. R. V. Ambartzumian and V.S. Letokhov, "Chemical and biochemical applications of lasers," Vol. III, ed. C. B. Moore (Academic Press, NY, 1977).

18. C. D. Cantrell, V. S. Letokhov and A. A. Makarov, "Coherent nonlinear optics," ed. M. S. Feld and V. S. Letokhov, Topics in Current Physics, Vol. 21 (SpringerVerlag, New York, 1980).

19. M. Quack, J. Chem. Phys. 69, 1282 (1978); and J. R. Barker, J. Chem. Phys. 72, 3686 (1980).

20. G. M. Stewart and J. D McDonald, J. Chem. Phys. 78, 3907 (1983).

21. R. E. Smalley, J. Phys. Chem. 86, 3504 (1982).

22. S. E. Stein and B. S. Rabinovitch, J. Chem. Phys. 58, 2438 (1973).

23. J. C. Jang, D. W. Setser and W. C. Danen, J. Am. Chem. Soc. 104, 5440 (1982).

24. D. M. Crane and T. L. Rose, J. Phys. Chem. 79, 403 (1975).

25. C. Galoy and J. C. Lorquet, Chem. Phys. Lett. 93, 26 (1982).

26. J. Troe, J. Chem. Phys. 66, 4758 (1977).

27. E. Hirota, J. Chem. Phys. 45, 1984 (1966).

28. J. R. Villarreal, J. Laane, S. F. Bush and W. C. Harris, Spect. Acta 35A, 331 (1979).

29. J. R. Durig, A. C. Shing, W. E. Bucey and C. J. Wurray, Spect. Acta 34A, 525 (1978).

30. S. J. Cyvin, Spect. Acta 16, 1022 (1960).

31. R. C. Lord and P. Venkateshwarlu, J. Opt. Soc. Am. 43, 1079 (1953).

32. L. M. Sverdlov and E. P. Krainov, Opt. and Spect. 7, 296 (1959).

33. M. C. Gower and K. W. Billman, Opt. Commun. 20, 123 (1977).

34. E. Borsella, R. Fantoni, A. Giaradini-Guidoni, D. Masci, A. Polucci and J. Reuss, Chem. Phys. Lett. 93, 523 (1982).

35. V. Del Bello, E. Borsella, R. Fantoni, A. Giardini-Guidoni and C. D. Cantrell, Chem. Phys. Lett. 114, 467 (1985).

36. K. S. Pitzer and W. D. Gwinn, J. Chem. Phys. 10, 428 (1942).

37. F. H. Dorer and B. S. Rabinovitch, J. Phys. Chem. 69, 1973 (1965).

38. C. M. Richards and J. R. Nielsen, J. Opt. Soc. Am. 40, 442 (1950); J. E. Kilpatrick and K. S. Pitzer, J. Research Nat. Bur. Stand. 38, 191 (1947).

39. C. S. Parmenter and B. M. Stone, J. Chem. Phys. 84, 4710 (1986); K. W. Holtzclaw and C. S. Parmenter, J. Chem. Phys. 82, 5284 (1985). 


\section{Appendix}

Here the treatment of internal rotors employed in density of states calculations is described briefly. Stein and Rabinovitch ${ }^{22}$ suggest precise computation of lower energy levels up to $1 \frac{1 / 2}{2}$ times the barrier height, with higher energy levels approximately by "Pitzer" free rotor. ${ }^{36}$

We have used the WKB quantization rule for calculating the hindered rotor levels up to the barrier height. The method is numerically analogous to the treatment suggested for anharmonic oscillators ${ }^{25}$ when the appropriate potential function is known. The WKB expression used is ${ }^{26}$

$$
(v+1 / 2)=\left(8 \operatorname{Im} / h^{2}\right)^{1 / 2} \int[E-V(\chi)]^{1 / 2} \mathrm{~d} \chi / 2 \pi
$$

where $v$ is the quantum-number, $I m$ is the effective moment of inertia of the rotor relative to the molecular frame and $V(\chi)$ is the angle $(\chi)$ dependent potential of the rotor. Integration is carried between the turning points (i.e., when $V(\chi)=E$ ) in a single well. Integrations were performed for several values of $E$ below the barrier and energy levels found by interpolating at integer values of $v$.

The conventional three fold potential function was used for the methyl rotors

$$
V(\chi)=V_{3}(1-\cos 3 \chi) / 2+V_{6}(1-\cos 6 \chi) / 2
$$

where $V_{3}$ is the barrier height. The value of $V_{6}$ was available only for propylene. ${ }^{27}$ It was found that the exclusion of the $V_{6}$ term in the potential had a minor effect on the energy levels of the hindered rotor and no discernible change occurred in the density of states in this molecule. Thus we have employed a one term potential for the rest of the cases. A degeneracy of 3 was used for the hindered levels of the methyl rotor. For the vinyl rotor a similar but two fold potential was used with a degeneracy of 2 for the hindered levels. All levels above the barrier were treated as doubly degenerate. The calculated hindered rotor levels of propylene compare well with the measured values of its first three levels reported in. ${ }^{27}$ 